\title{
Topical Application of Adipose Tissue-Derived Mesenchymal Stem Cells Ameliorates Renal Ischemia-Reperfusion Injury in Rats
}

Ping-kuen Lam ${ }^{1,2}$, Chi-fai NG ${ }^{1,2^{\star}}$, Wai-lun Tang ${ }^{3}$, Anthony WI Lo ${ }^{4}$, Cindy SW Tong ${ }^{1,2}$, Don WC Chin ${ }^{1,2}$, Kenneth HK Wong ${ }^{4}$, Kin KY Lo ${ }^{1,2}$, Richard KW Choy ${ }^{5}$, Eddie SY Chan ${ }^{1}$ and Paul BS Lai ${ }^{1,2}$

${ }^{1}$ Department of Surgery, The Chinese University of Hong Kong, China

${ }^{2}$ Chow Tai Fook - Cheng Yu Tung Surgical Stem Cell Research Center, The Chinese University of Hong Kong, China

${ }^{3}$ Department of Clinical Pathology, Pamela Youde Nethersole Eastern Hospital, Hong Kong, China

${ }^{4}$ Department of Anatomical and Cellular Pathology, The Chinese University of Hong Kong, China

${ }^{5}$ Department of Obstetrics and Gynecology, The Chinese University of Hong Kong, China

\begin{abstract}
Ischemia-Reperfusion Injury (IRI) was induced by clamping bilateral renal pedicles simultaneously for 60-min using bulldog clamps in Sprague-Dawley rats. They were then randomized into five groups: Group-l-3 $\times 10^{6} \mathrm{MSCs}$ were topically applied to the surface of each kidney with a layer of fibrin sealant, Group-II-only fibrin sealant was added, Group-III-only $3 \times 10^{6} \mathrm{MSC}$ were added, Group-IV-1 $\times 10^{6} \mathrm{MSC}$ were injected directly into tail-vein and Group- $V$ received no additional treatment (control). Serum creatinine in Group-I at Day-3 was significantly lower than the other groups. By Day-7, survival rates of animals with renal IRI were $81.3 \%$ in Group-I, $31.3 \%$ in Group-II, $37.6 \%$ in Group-III, 30.8\% in Group-IV, and 25\% in Group-V. At Day-3, histology of kidneys from Group-I showed less tubular necrosis and interstitial inflammation, when compared to Group-V. Reverse transcription polymerase chain reaction showed down-regulation of caspase-3 (indicator of apoptosis) and endothelin-1 (indicator of endothelial damage) and up-regulation of NQO-1 (antioxidative molecule) $(p<0.05)$. A total of 4168 unique genes of the topical MSCs growing on the surface of ischemic kidneys were differentially regulated with reference to the MSC pellet (greater than twofold change; $p<0.05)$. In conclusion, application of topical MSCs with fibrin sealant could improve outcomes of renal IRI ischemia in rats.
\end{abstract}

Keywords: Adipose stem cells; Differentiation; Mesenchymal stem cells (MSCs); Ischemic reperfusion injury; Kidney injury

Abbreviations: ADMSC: Adipose-derived Mesenchymal Stem Cells; FS: Fibrin Sealant; IRI: Ischemia Reperfusion Injury; MSCs: Mesenchymal Stem Cells; RT-PCR: Reverse Transcription Polymerase Chain Reaction

\section{Introduction}

Ischemia Reperfusion Injury (IRI) is one of the leading causes of acute kidney injury. Renal IRI can occur as a result of renal surgery (kidney transplantation, partial nephrectomy), other major surgery (such as major cardiac surgery, aortic surgery), or it may be due to prerenal causes (such as decompensated heart failure or sepsis, etc.). It is characterized by a period of restricted blood flow to the kidney, and is followed by the acute/ sudden restoration of blood flow, which leads to a series of inflammatory reactions, including free radical formation and activation of cytokines and leukocytes [1]. In patients with severe IRI, proximal tubular epithelial cells and endothelium undergo necrosis, apoptosis, and detachment [2,3], resulting in postoperative renal dysfunction, delayed graft function, and even long-term renal failure or graft loss. Despite advanced preventive therapies such as ischemic preconditioning and metabolic intervention, IRI still causes significant morbidity and mortality $[4,5]$.

Mesenchymal Stem Cells (MSCs) have attracted great scientific and public interest because of their relatively easy access and their capacity for multipotentiality and self-renewal [6,7]. Renoprotective effects have been shown in preclinical studies [8-13]. It is believed that MSCs ameliorate renal injury by direct differentiation into tubular epithelial cells or by the release of paracrine/ endocrine factors that restore renal structure and function [8,9]. MSCs provide a promising multifactorial treatment approach, in contrast to pharmacologic agents, which usually target a single pathway in the pathophysiology of a given disease. Currently, MSCs are commonly administrated by intravenous, intra-arterial, or intraparenchymal injection. However, most MSCs delivered through the systematic circulation are trapped in the lung, liver, and spleen [14]. Although injection of MSCs into renal artery may improve MSC uptake, this approach is technically more difficult and carries a potential risk of blockage of the intrarenal vessels. Direct injection of MSCs into renal parenchyma may result in tissue injury and severe bleeding while accomplishing only very localized and limited delivery. It is therefore not advised in clinical settings. A safer and more effective delivery route for MSCs to injured kidneys would be highly desirable. Our previous studies have demonstrated the concept of topical application of MSCs in experimental models of somatic organs, including the brain, liver, and kidney $[15,16]$. In this study, we sought to investigate the renoprotective effects of topically applied MSCs in a rodent model of bilateral IRI.

\section{Materials and Methods}

All procedures involving animals were conducted in accordance with the guidelines in local government regulations, and the study

*Corresponding author: Professor Chi-fai NG (MD), SH Ho Urology Centre, Department of Surgery, Prince of Wales Hospital, The Chinese University of Hong Kong, China, Tel: 852-35052625; Fax: 852-26377974; E-mail: ngcf@ surgery.cuhk.edu.hk

Received October 17, 2017; Accepted October 24, 2017; Published October 31 2017

Citation: Lam P, Chi-fai NG, Tang W, Lo AWI, Tong CSW, et al. (2017) Topical Application of Adipose Tissue-Derived Mesenchymal Stem Cells Ameliorates Renal Ischemia-Reperfusion Injury in Rats. J Stem Cell Res Ther 7: 404. doi: 10.4172/2157-7633.1000404

Copyright: (C) 2017 Lam P, et al. This is an open-access article distributed under the terms of the Creative Commons Attribution License, which permits unrestricted use, distribution, and reproduction in any medium, provided the original author and source are credited. 
was approved by our institution's Animal Experimentation Ethics Committee.

\section{Adipose-Derived MSCs (ADMSC)}

Adipose-derived MSCs that expressed Green Fluorescent Protein (GFP) (SD-Tg[CAG-EGFP] CZ-0040sb; SLC Inc., Japan) were harvested from the subcutaneous fat of male transgenic Sprague-Dawley rats $(300$ to $350 \mathrm{~g}$ ). The subcutaneous adipose tissue was washed extensively with sterile phosphate-buffered saline solution and then treated with $0.1 \%$ collagenase (type I; Sigma-Aldrich) in phosphate-buffered saline solution for $30 \mathrm{~min}$ at $37^{\circ} \mathrm{C}$ with gentle agitation. After filtration through $100-\mu \mathrm{m}$ mesh filter to remove any debris, the filtrate was washed three times and completely suspended in Dulbecco's modified Eagle's medium supplemented with $10 \%$ fetal bovine serum, 100 units $/ \mathrm{ml}$ of penicillin, $100 \mu \mathrm{g} / \mathrm{ml}$ of streptomycin, and $2 \mathrm{mM}$ of L-glutamine. The cultures were maintained in an incubator in a humidified atmosphere of $5 \% \mathrm{CO}_{2}$.

\section{Cell phenotyping}

MSCs were grown for three to five passages and then harvested with $0.25 \%$ trypsin/ ethylenediaminetetraacetic acid and characterized by flow cytometer with a FACScan argon laser (BD Biosciences, San Jose, CA). The trypsinized cells were washed and centrifuged for $10 \mathrm{~min}$ at low speed, and then $1 \times 10^{6}$ cells were fixed in 3\% paraformaldehyde for $30 \mathrm{~min}$ at $4^{\circ} \mathrm{C}$. The cells were labeled with phycoerythrin-conjugated antibodies against CD29, CD34, CD45, CD90 and CD105 (Abcam, Cambridge, UK). Isotype-matched negative controls were used to assess the background fluorescence. The data were analyzed with CellQuest software (Becton Dickinson).

\section{Adipogenic, chondrogenic, and osteogenic differentiation potential}

MSCs were seeded at 5000 cells $/ \mathrm{cm}^{2}$ and cultured in adipogenic, chondrogenic, and osteogenic differentiation culture media according to the manufacturer's protocols (Invitrogen, Thermo Fisher Scientific). The differentiated adipocytes were stained with oil red $\mathrm{O}$, chondrocytes with alcian blue, and osteocytes with alizarin red S stain to identify intracytoplasmic lipids, extracellular glycosaminoglycans, and calcium deposits, respectively. All chemicals were purchased from SigmaAldrich.

\section{Kidney IRI model}

Wild-type female Sprague-Dawley rats (6 weeks of age; 200 to 250 g) were used in the experiment. The animals were anesthetized by the intraperitoneal injection of ketamine and xylazine $(60 \mathrm{mg} / \mathrm{kg}$ and 3 $\mathrm{mg} / \mathrm{kg}$, respectively). The renal IRI model was similar to the method described by Aydin et al. with some minor modifications [17]. In brief, bilateral lumbar incisions, via a single $2-\mathrm{cm}$ midline incision, were created for access, and the kidneys were identified and mobilized. Bilateral renal pedicles were clamped simultaneously with atraumatic vascular bulldog clamps for $60 \mathrm{~min}$. During this ischemic period, the kidneys were constantly kept moist with saline gauze. After $60 \mathrm{~min}$, the bulldog clamps were removed and successful reperfusion was confirmed by visual assessment of the revascularization of the kidney. Throughout the experiment, the rats were placed under a lamp to maintain their body temperature. Blood was collected for assessment from the tail vein immediately after reperfusion.

\section{Transplantation of MSCs}

After the confirmation of revascularization of ischemic kidney, rats were immediately randomly assigned to five different groups. In Group
I, $3 \times 106$ MSCs suspended in $200 \mu$ of saline solution were topically applied to the surface of each kidney. The MSCs were then maintained in position with a thin layer $(200 \mu \mathrm{l})$ of fibrin sealant (FS) (TISSEEL, Baxter, US) (both stem cell and fibrin). In Group II, a thin layer of FS was added to each kidney (fibrin only). In Group III, $3 \times 106$ MSCs alone were added to each kidney (stem cell only). In Group IV, $1 \times 106$ MSCs were injected directly into the tail vein. Group V included control animals without any treatment. For Group I , II, III and V, 20 animals were used in each group. However, for Group IV, there was significant number of animal death after intravenous injection (explanation will be elaborated in the result and discussion section), 30 animals were used for this group.

After completion of the procedures, the kidneys were returned to their original position. All incisions were closed with suture. All animals were inspected daily after IRI for their general condition, and their body weight was recorded. Any rat that developed noticeable signs of distress was euthanized. Blood was collected from the tail vein, before surgery and on Day 1, Day 3 and Day 7 for renal function assessment.

\section{Histologic analysis.}

Four animals from each group were sacrificed at Day 3 and Day 7 after MSC transplantation for histology assessment. Paraffin-embedded sections were stained with hematoxylin and eosin. Tubular necrosis, interstitial inflammation, intratubular cast formation, brush border loss, cell shedding, macrophage infiltration, apoptosis, and dystrophic calcification were assigned semi-quantitative histologic scores by two independent pathologists, as previously described with modification [18]. Scores ranged from 0 to 3 and were defined as none, mild, moderate, and severe respectively. The pathologists were blinded to the treatment received by the animals. Immunohistochemical staining using anti-GFP was performed on paraffin sections for the trafficking of the topical MSCs.

\section{Reverse transcription polymerase chain reaction (RT-PCR)}

RNA $(2 \mu \mathrm{g})$ was extracted from snap-frozen kidney tissue from Group I animals sacrificed on Day 7, and was used for cDNA synthesis using a transverse transcription kit (Applied Biosystems, USA). Amplification was performed using primers designed for caspase-3, endothelin-1, and NQO-1 (Supplementary Table 1).

\section{Microarray}

RNA extraction, labeling, and hybridization: In a separate study, the MSC populations were harvested from the surface of the ischemic kidneys $(\mathrm{N}=3)$ and normal kidneys $(\mathrm{N}=3)$ on Day 3 after topical application with FS. Total RNA was isolated using a TRIzol ${ }^{\circledR}$ Plus RNA Purification kit, and extraction was performed according to the manufacturer's instructions (Invitrogen, Thermo Fisher Scientific). The samples were labeled and hybridized onto an Agilent $4 \times 44 \mathrm{~K}$ Rat Gene Expression Microarray according to the manufacturer's instructions. The images were analyzed with Agilent Feature Extraction 11.0.

Gene expression, data normalization: Data obtained from Feature Extraction were imported to GeneSpring GX 13.0 (Agilent Technologies, Santa Clara, CA) for the 75th percentile shift, and the baseline median was calculated to normalize all of the samples. Genes with changes greater than twofold and $p$ values of less than 0.05 in the MSC populations on the ischemic and normal kidneys with reference to the MSC pellet were analyzed. Pathways were predicted using the WikiPathway database. The results of the microarray were validated by 
Citation: Lam P, Chi-fai NG, Tang W, Lo AWI, Tong CSW, et al. (2017) Topical Application of Adipose Tissue-Derived Mesenchymal Stem Cells Ameliorates Renal Ischemia-Reperfusion Injury in Rats. J Stem Cell Res Ther 7: 404. doi: 10.4172/2157-7633.1000404

Page 3 of 9

\section{RT-PCR.}

\section{Statistical analysis}

Data were expressed as the mean \pm SD. One-way analysis of variance was used to compare the differences between the groups. For multiple comparisons of serum creatinine level, Dunnett's test was used to determine which groups are significantly different from Group I. P values of less than 0.05 indicated a significant difference.

\section{Results}

\section{Characterization of adipose-derived MSCs}

In this study, MSCs isolated from the adipose tissue of transgenic GFP-SD rats adhered to the plastic culture flasks and exhibited a spindleshaped morphology (Figure 1A). Flow cytometric analysis showed that the MSCs strongly expressed CD29 and CD90 but were negative for CD105, CD34 and CD45 (Figure 1B). The MSCs demonstrated in vitro potential to differentiate into adipocytes, chondroblasts, and osteoblasts under specific differentiating environments (Figures 1C, 1D and 1E).

\section{Topical MSCs improved renal function and survival}

In this study, $60 \mathrm{~min}$ of bilateral ischemia caused severe acute renal injury. The baseline serum creatinine level for the animals was $16 \pm 4 \mu \mathrm{mol} / \mathrm{L}$. On Day 1 after renal IRI, the creatinine levels were significantly elevated over baseline in all groups of animals. On Day 3 , the renal function of animals treated with topical MSC and FS (Group I) had improved and the mean serum creatinine level was $241 \pm 102$ $\mu \mathrm{mol} / \mathrm{L}$, which was significantly lower than in those of Group II (446 \pm $82 \mu \mathrm{mol} / \mathrm{L}, \mathrm{p}<0.001)$, Group III $(513 \pm 55 \mu \mathrm{mol} / \mathrm{L}, \mathrm{p}<0.001)$, Group IV $(355 \pm 105 \mu \mathrm{mol} / \mathrm{L}, \mathrm{p}=0.007)$ and Group V $(482 \pm 75 \mu \mathrm{mol} / \mathrm{L}, \mathrm{p}<0.001)$ (Figure 2). On Day 7, the serum creatinine level of animals in Group I had further improved to $139 \pm 58 \mu \mathrm{mol} / \mathrm{L}$, and was again significantly lower than the other four groups. While the serum creatinine levels of Group II $(574 \pm 180 \mu \mathrm{mol} / \mathrm{L})$, III $(574 \pm 180 \mu \mathrm{mol} / \mathrm{L})$ and V $(516 \pm$ $56 \mu \mathrm{mol} / \mathrm{L})$ continually increased on Day 7 , serum creatinine level of Group IV improved to $296 \pm 93 \mu \mathrm{mol} / \mathrm{L}$ (Figure 2).

Forty-three percent of the animals (13 out of 30 rats) in Group IV died immediately after intravenous injection of the MSCs because a large quantity of the infused MSCs were trapped by the pulmonary capillaries, leading to interstitial pneumonitis (Figure 3A and 3B). On Day 2, the survival rate in Group I was $100 \%$, which was higher than

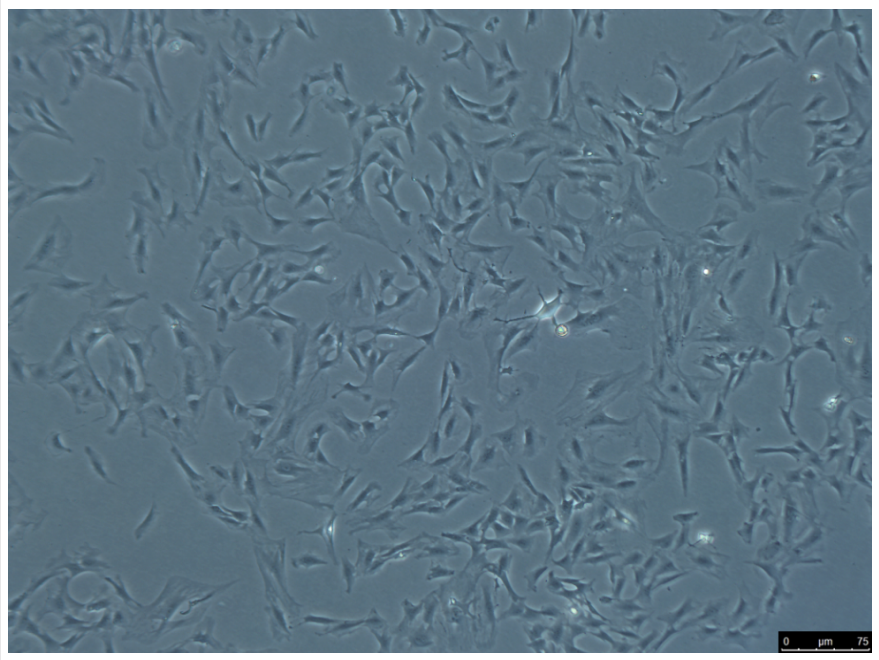

Figure 1A: Adherent MSC culture shows spindle-shaped morphology by phase-contrast microscopy $(\times 50)$.
CD29

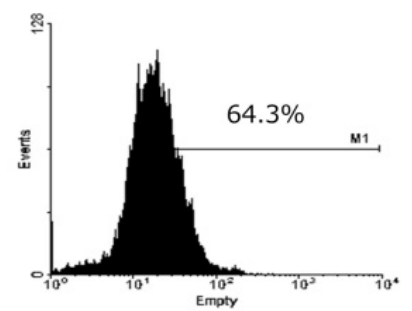

CD105

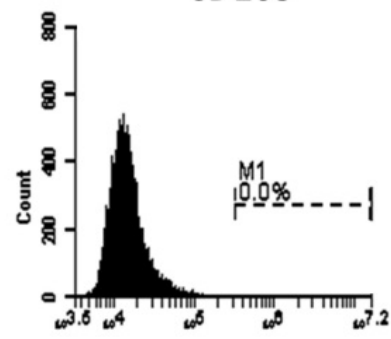

CD90

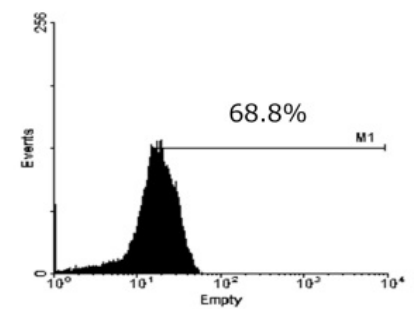

CD34

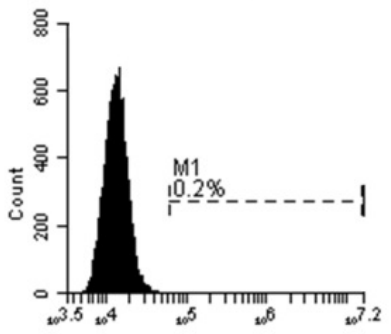

CD45

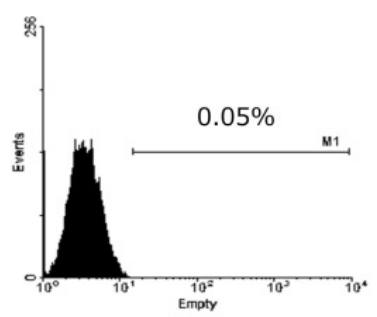

Figure 1B: Flow cytometric analysis of MSCs. 
Citation: Lam P, Chi-fai NG, Tang W, Lo AWI, Tong CSW, et al. (2017) Topical Application of Adipose Tissue-Derived Mesenchymal Stem Cells Ameliorates Renal Ischemia-Reperfusion Injury in Rats. J Stem Cell Res Ther 7: 404. doi: 10.4172/2157-7633.1000404

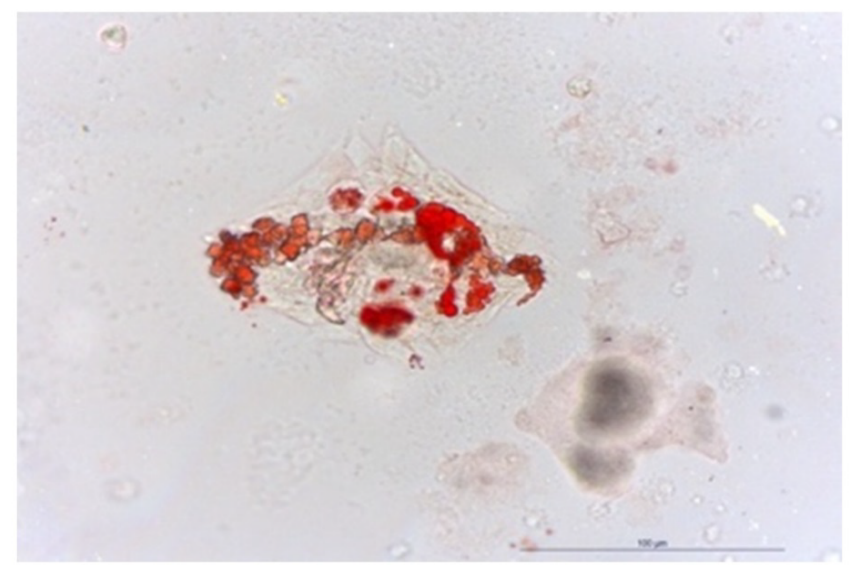

Figure 1C: Lipid-containing cytoplasmic vacuoles (Oil Red x400)

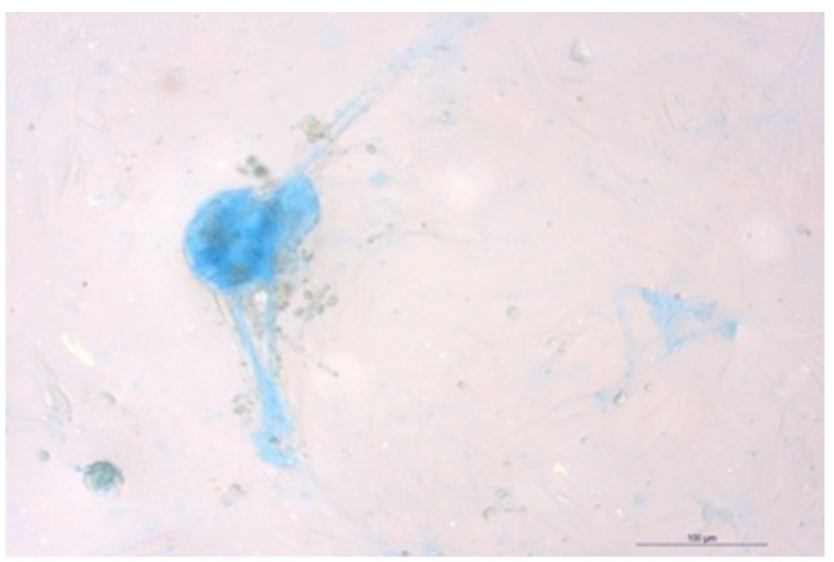

Figure 1D: Rich glycosaminoglycan matrix (Alcian Blue x200)

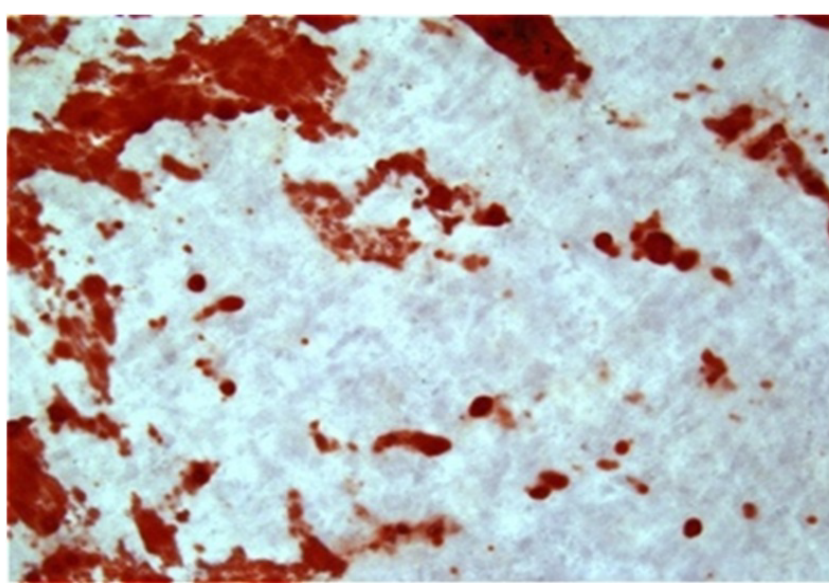

Figure 1E: Calcium-containing nodules (Alizarin Red x200).

that seen in Groups II (80\%), III (80\%), IV (82.5\%, excluding those rats died immediately after injection; 56.7\%, including all rats) and Group $\mathrm{V}(75 \%)$. At Day 7, the mortality rates in Groups II to V were high (50\% to $60 \%)$. Most of these animals were killed because they suffered from

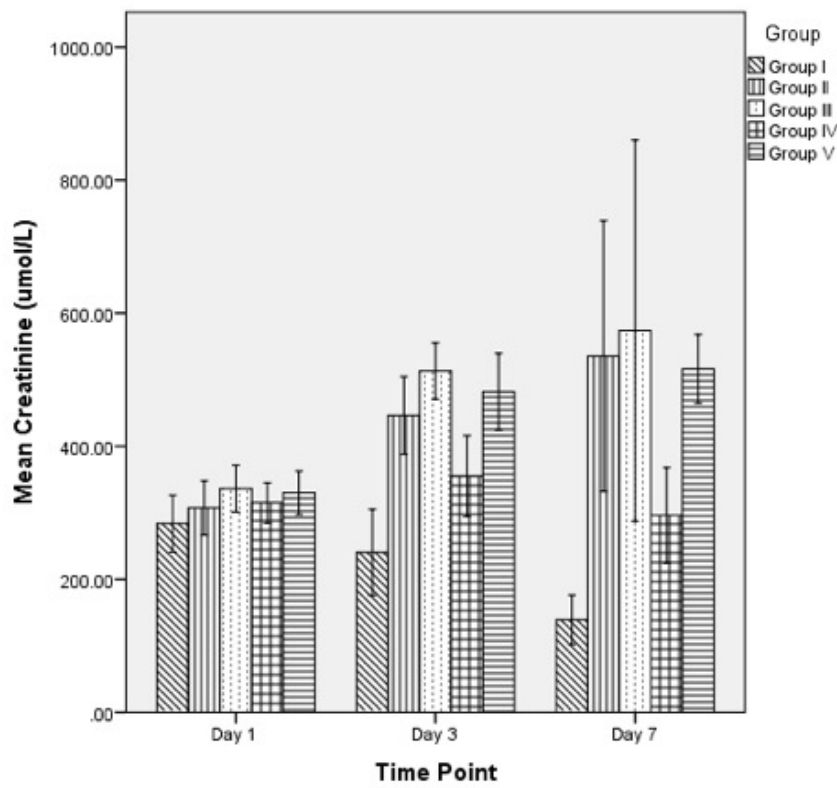

Figure 2: Serum creatinine level in the five experimental groups on Day 1, Day 3 and Day 7 . Group I had a significantly lower creatinine level than the other groups $(p<0.05)$. The mean baseline serum creatinine level was $16 \pm 4 \mu \mathrm{mol} / \mathrm{L}$ (not shown in the chart).

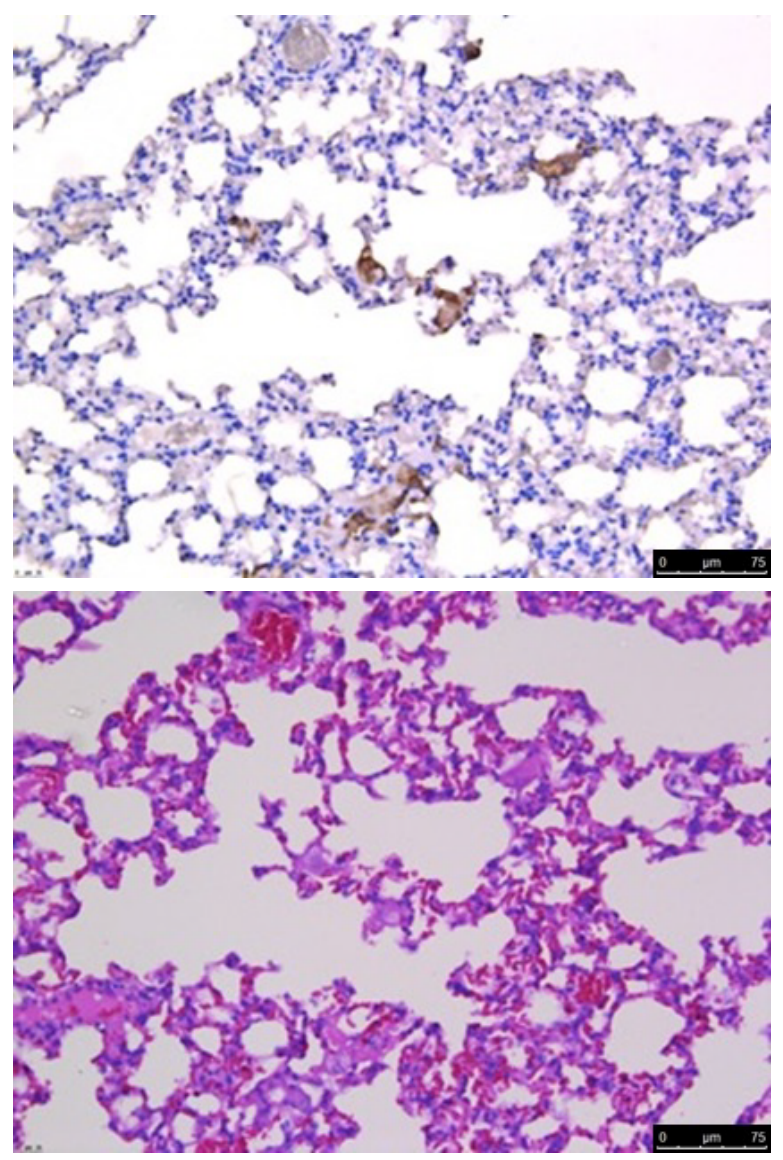

Figure 3: Systemic infusion of MSCs via tail vein caused diffuse interstitial pneumonia in the lung (3A, immunohistochemical stain with anti-GFP antibody, $200 \times)(3 B, H \& E, 200 \times)$. 
a great loss of body weight ( $>30 \%)$, but the survival rate in Group I was $85 \%$ (Table 1).

\section{Topical MSCs attenuated renal IRI}

In this study, bilateral clamping for 60 min caused severe tubular injury in the control animals (Group V; Figure 4A). Topical application of $3 \times 10^{6}$ MSCs (Group I) attenuated tubular necrosis, interstitial inflammation, intratubular cast formation, brush border loss, cell shedding, and apoptosis (Figure 4B). In Group I, the kidneys had healed with mild tubular necrosis at 10 weeks after IRI (Figure 4C).

The trafficking of the topically applied MSCs was examined by immune-histochemical staining using anti-GFP. At Day 3 after topical application of MSCs, only a few GFP-positive cells were found in the outer medullary cortex in the rats in Group I (Figure 4D). These homed cells show no signs of differentiation. No viable GFP-positive cells were observed in the renal parenchyma at Day 7. When MSCs alone were applied to the kidneys (Group III), most of the MSCs were detached from the recipient surface by Day 3. No GFP-positive cells were found in the renal parenchyma in Groups II, IV, or V.

\section{Down-regulation of apoptosis and inflammation}

RT-PCR analysis of the kidney tissue was performed in animals from Groups I and V on Day 3. From the analysis, the mRNA expression of caspase-3 (indicator of apoptosis) and endothelin-1 (indicator of endothelial damage i.e. pro-inflammation marker) in Group I was suppressed compared to Group V (both $\mathrm{p}<0.05$ ). In contrast, the expression of NQO-1 (an anti-oxidative marker) was upregulated when compared with Group V $(\mathrm{p}=0.04)$. Moreover, a trend of reduced expression of pro-inflammatory TNF- $\alpha$ and increased expression of pro-angiogenic endothelial nitric oxide synthase was seen, but the differences were not statistically significant (Table 2).

\section{Fifteen signaling pathways were activated in the topical MSCs on the surface of kidneys with IRI}

The transcriptome of MSCs on the surface of kidneys with IRI (Group I) and normal kidneys was investigated by microarray three days after topical application. More than 30,000 gene probes were examined. Unsupervised hierarchical cluster analysis demonstrated differential expression of 13,908 genes of the topical MSCs during early interaction with kidneys with IRI when compared with the ADMSC pellet (change greater than twofold; $\mathrm{p}<0.05$; Figure $5 \mathrm{~A}$ ). The differentially expressed genes were annotated with Gene Ontology (GeneSpring GX 13.0). They represented different functional annotations, including extracellular region, response to stress (acute inflammatory response, defense response), regulation of hydrolase activity, and regulation of endopeptidase activity. The findings on differential gene expression were consistent with the RT-PCR validation (Supplementary Table 2). A Venn diagram revealed 10,306 unique genes differentially expressed in the MSCs on kidneys with IRI and 3602 differentially expressed genes detected in the MSC populations on kidneys with IRI and normal kidneys (Figure 5B). Fifteen signaling pathways were considered to be activated when "Find Significant Pathway" based on the database of WikiPathways was used to analyze the pathways (Table 3 ).

\section{Discussion}

Renal IRI is a common complication of various surgical procedures and medical conditions. It triggers a number of pathological events, including macrophage/ neutrophil infiltration and production of oxygen free radicals and pro-inflammatory mediators. Functional and structural changes also occur, including tubular epithelial cell necrosis and obstruction of tubules by intratubular casts and endothelial cell damage, which lead to acute renal dysfunction in patients. For example, delayed graft function is observed in $20 \%$ to $80 \%$ of kidney transplant recipients [19]. As a result, many patients might require temporary dialysis until renal function recovered. Although many potential therapeutic approaches have been proposed, including phosphodiesterase inhibition and renin-angiotensin system modulation, evidence to support their routine clinical use is still lacking [1]. Therefore, there is a pressing need for better treatment for renal IRI. The use of MSCs have been reported to protect against ischemiareperfusion acute kidney injury (IRI) and accelerate repair process. This cell therapy significantly improved renal function, reduced intratubular cast formation, ameliorated acute tubular epithelial cell necrosis and mitigated macrophage infiltration $[20,21]$. Therefore MSC therapy may provide a new hope to patients suffering from IRI.

MSC in bone marrow was first discovered in 1970s [22]. Bonemarrow-derived mesenchymal stem cell (BM-MSC) could undergo multi-directional differentiation. Unfortunately, harvesting bone marrow cells is a painful and not-risk-free procedure. The yield of stem cells can be variable as the density of MSCs is about 1 in 105 cells, rendering extra ex vivo expansion steps necessary. MSCs are also found in mature tissues such as adipose tissue, and umbilical cord, etc. [23]. Comparative analysis showed that regarding the morphology, immune phenotype, and differentiation capacity, the MSCs derived from adipose tissue are similar from those obtained from MSC obtained from bone marrow or from the umbilical cord [24]. Since MSCs are more abundant in the adipose tissue [25], adipose-derived mesenchymal stem cell (ADMSC) provides a good source of MSCs for laboratory research and clinical usage.

A reliable mode of MSC delivery is important for the success of the therapy. MSCs can be delivered to the target organ either systemically (i.e. intravascular injection) or locally (direct delivery to the targeted organ). Intravascular injection can be done either transarterially [2628] or transvenously [29,30]. However, the injected MSCs may only have a short transit through the kidney and result in inadequate cell delivery to the injured kidney [14]. Either approach also results in significant entrapment of cells in lung, liver and spleen $[31,32]$. From

\begin{tabular}{|c|c|c|c|c|}
\hline Group of animals & Day 1 & Day 2 & Day 3 & Day 4\# \\
\hline Group I & $100 \%$ & $100 \%$ & $95 \%$ & $87.5 \%$ \\
\hline Group II & $85 \%$ & $80 \%$ & $65 \%$ & $43.8 \%$ \\
\hline Group III & $90 \%$ & $80 \%$ & $31.3 \%$ \\
\hline Group IV & $56.7 \%^{*}\left(100 \%^{* *}\right)$ & $46.7 \%^{*}\left(82.4 \%^{* *}\right)$ & $46.7 \%^{*}\left(82.4 \%^{* *}\right)$ & $30.8 \%^{*}\left(61.5 \%^{* *}\right)$ \\
\hline Group V & $90 \%$ & $75 \%$ & $30.8 \%^{*}\left(61.5 \%^{* *}\right)$ \\
\hline
\end{tabular}

* Included those animal died immediately after intravenous MSC injection. i.e. total 30 rats.

** Excluded those animal died immediately (13 rats) after intravenous MSC injection, i.e. 17 rats remained.

\# The 4 animals were sacrificed on Day 3 for histological assessment. 
Citation: Lam P, Chi-fai NG, Tang W, Lo AWI, Tong CSW, et al. (2017) Topical Application of Adipose Tissue-Derived Mesenchymal Stem Cells Ameliorates Renal Ischemia-Reperfusion Injury in Rats. J Stem Cell Res Ther 7: 404. doi: 10.4172/2157-7633.1000404

Page 6 of 9
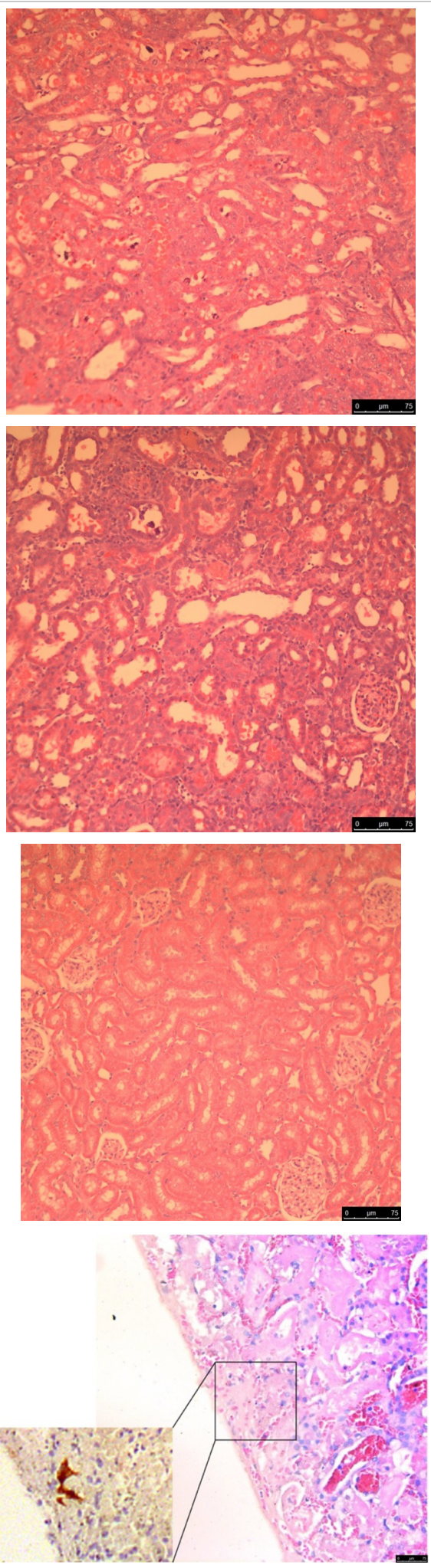

Figure 4: Acute kidney injury, Day 3 (group V). Marked tubular necrosis, cell shedding, intratubular casts, mitoses, and dystrophic calcification were seen (4A, H\&E, 200×). Topical application of MSCs (group I) on Day 7. Attenuation of tubular necrosis, cell shedding, intratubular casts, and dystrophic calcification were observed (4B, H\&E 200X). Topical application of MSCs at week 10 Features of acute kidney injury became inconspicuous during the healing stage (4C, H\&E, 200x). GFP-positive cells were observed in the renal cortex (4D, immunohistochemical stain; H\&E, $200 \times$ ).

\begin{tabular}{|c|c|c|}
\hline & Fold Change & P-value \\
\hline Caspase-3 & $0.36 \downarrow$ & 0.03 \\
\hline Endothelin-1 & $0.28 \downarrow$ & 0.01 \\
\hline NQO-1 & $1.15 \uparrow$ & 0.04 \\
\hline
\end{tabular}

Table 2: mRNA expression associated with apoptotic, inflammatory, and antioxidative mediators in Group I with reference to Group V.

our study, more than $40 \%$ animals died immediately after the systemic infusion of MSCs because of undesirable pneumonic reactions to trapped MSCs in the lung, which highlights the potential complications of this relatively simple and seemingly safe route of intravenous MSC infusion. Although direct intra-renal artery injection may improve the kidney uptake of MSCs, but there is a potential risk of blocking of intrarenal vessels by MSCs, causing further ischemic insult. Moreover, the surgical technique is complicated and may cause direct damage to the renal artery.

Due to its hemostatic and sealing properties, Fibrin Sealant (FS) (also refereed as fibrin glue or fibrin tissue adhesive) is widely used in many areas of surgery [33-35]. FS contains two major components (thrombin and highly concentrated fibrinogen) that replicate and augment the final stage of the coagulation cascade - the cleavage of fibrinogen into fibrin by the action of thrombin, when mixed together. It is also used as a carrier for cultured keratinocytes, in which the cells are pre-mixed with fibrin component of FS, to surgical or burn wounds to facilitate wound healing [36]. The application of FS has been extended to tissue engineering of stem cells for bone tissue and nerve regeneration [37,38]. MSCs are pre-mixed with FS and the mixture is then injected into the sites of interest. It is believed that the fibrin extracellular matrix provides a three-dimensional template for the maintenance and proliferation of the transplanted MSCs. The fibrinstabilizing factor XIII of FS also favors migration of undifferentiated MSCs on the highly cross-linked matrix and facilitates cellular proliferation and differentiation into estrogenic lineage [39].

Our group is the first research group to apply MSCs onto the surface of injured organs directly by this approach to increase the availability of MSCs to inured organs [15,16]. There are several advantages for our approach. The method is simple, with no additional trauma or major complications to the injured organs. Large amount of MSCs can be readily delivered to the targeted organs with a simple surgical procedure. Repeated applications are also possible and relatively straightforward. From our results, the combination of MSCs with FS (Group I) provided the best recovery of renal function and survival when compared to the other treatment arms at Day 3 and 7 after IRI. This supported topical application of MSCs with FS is both a feasible and safe approach for treating IRI in kidney in this rat model, especially when compared to the intravenous application method (Group IV).

As shown in our study and other studies, MSCs treatment could help to improve the recovery of kidney in IRI model. However, the therapeutic mechanism remains unclear. In our study, only very few topical MSCs were observed in the renal parenchyma. Moreover, there was also no evidence of trans-differentiation of the homed MSCs to any kidney-specific cell type (data not shown). These observations were consistent with the literature. Transplantation of ADMSC via intra-renal administration did not cause local differentiation toward adipose cells [40]. Although most of the topically applied MSCs were observed to be remained on the surface of the recipient kidney in our study, the potential biological roles of these MSC should not be overlooked. It was postulated these MSCs might execute their biologic roles via paracrine and/or endocrine pathways, including mitogenic, antiapopotic, anti-inflammatory and angiogenic effects to support the 
Citation: Lam P, Chi-fai NG, Tang W, Lo AWI, Tong CSW, et al. (2017) Topical Application of Adipose Tissue-Derived Mesenchymal Stem Cells Ameliorates Renal Ischemia-Reperfusion Injury in Rats. J Stem Cell Res Ther 7: 404. doi: 10.4172/2157-7633.1000404
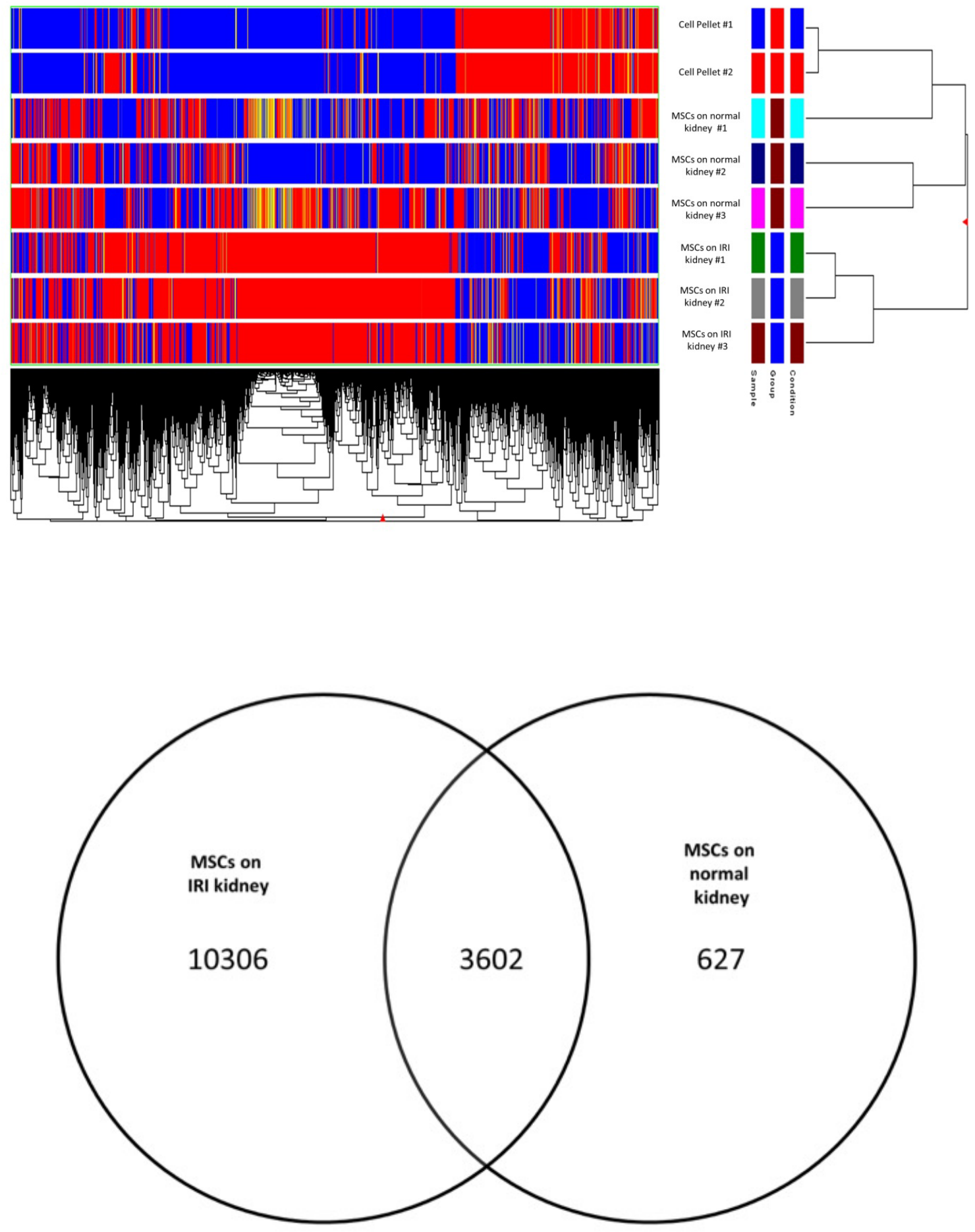

Figure 5: Hierarchical clustering of gene expression of MSCs after topical application on kidneys with IRI and normal kidneys. Down-regulated genes are shown in blue and up-regulated genes are shown in red (5A). Venn diagram illustrates the number of genes that were either up- or down-regulated in topical MSCs on kidneys with IRI and normal kidneys. Genes in the overlapping area showed altered expression under both conditions (5B) 
Citation: Lam P, Chi-fai NG, Tang W, Lo AWI, Tong CSW, et al. (2017) Topical Application of Adipose Tissue-Derived Mesenchymal Stem Cells Ameliorates Renal Ischemia-Reperfusion Injury in Rats. J Stem Cell Res Ther 7: 404. doi: 10.4172/2157-7633.1000404

Page 8 of 9

\begin{tabular}{|c|c|c|c|}
\hline Pathway & p-value & Matched Entities & Pathway Entities \\
\hline Rn_GPCRs,_Class_A_Rhodopsin-like_WP473_72158 & 8.37E-21 & 183 & 229 \\
\hline Rn_Peptide_GPCRs_WP131_71770 & $6.30 \mathrm{E}-08$ & 56 & 69 \\
\hline Rn_GPCRs,_Other_WP409_71799 & $3.25 \mathrm{E}-06$ & 57 & 75 \\
\hline Rn_Complement_and_Coagulation_Cascades_WP547_69384 & $2.79 E-04$ & 41 & 62 \\
\hline Rn_Cholesterol_Biosynthesis_WP461_71765 & $6.07 E-04$ & 14 & 15 \\
\hline Rn_Inflammatory_Response_Pathway_WP40_41738 & 0.00 & 23 & 30 \\
\hline Rn_Cholesterol_metabolism_WP659_69435 & 0.00 & 19 & 23 \\
\hline Rn_Blood_Clotting_Cascade_WP255_71806 & 0.01 & 16 & 20 \\
\hline Rn_Brain_derived_neurotrophic_factor_WP2148_70121 & 0.01 & 9 & 10 \\
\hline Rn_Complement_Activation,_Classical_Pathway_WP81_69440 & 0.01 & 13 & 16 \\
\hline Rn_Serotonin_and_anxiety_WP2132_58530 & 0.01 & 11 & 13 \\
\hline Rn_Monoamine_GPCRs_WP276_69439 & 0.02 & 23 & 33 \\
\hline Rn_Metapathway_biotransformation_WP1286_69345 & 0.03 & 81 & 143 \\
\hline Rn_Cytokines_and_Inflammatory_Response_(BioCarta)_WP271_41782 & 0.05 & 18 & 26 \\
\hline Rn_Retinol_metabolism_WP1297_71769 & 0.05 & 25 & 38 \\
\hline
\end{tabular}

Table 3: Fifteen signaling pathways were activated in topical MSC on the kidneys with IRI.

regeneration of local kidney cells $[8,9,26,41,42]$. In fact, from our study, we had demonstrated downregulation of the expressions of caspase-3 (indicator of apoptosis) and endothelin-1 (indicator of endothelial damage), and upregulation of the expression of NQO-1 (anti-oxidative marker) in kidneys treated with topical MSCs. Furthermore, the signaling pathways of topical MSCs on the surface of ischemic kidneys in this study were significantly activated. These findings concurred with the literature that the beneficial effects of MSCs could be related to its paracrine actions $[8,9,11,13,40]$. However, the underlying interaction between the topical MSCs and ischemic renal parenchyma remains to be determined.

\section{Conclusion}

In conclusion, topical application of MSCs is a direct and effective transplantation method and could be applied to the kidney surface to promote its recovery after IRI in our rat model.

\section{Conflict of Interest}

The authors declare that there is no conflict of interest regarding the publication of this article.

\section{Author's Contributions}

Ping-kuen LAM: concept and design, provision of study materials, collection and/or assembly of data

Chi-fai NG: concept and design, manuscript writing, final approval of manuscript

Wai-lun TANG: data analysis and interpretation

Anthony WI LO: data analysis and interpretation

Cindy SW TONG: collection and/ or assembly of data

Don WC CHIN: collection and/or assembly of data

Kenneth HK WONG: collection and/or assembly of data

Kin KY LO: collection and/or assembly of data

Richard KW CHOY: concept and design, provision of study materials

Eddie SY CHAN: concept and design

Paul BS LAI: concept and design, administrative support, final approval of manuscript

\section{References}

1. Malek M, Nematbakhsh M (2015) Renal ischemia/reperfusion injury; from pathophysiology to treatment, Journal of Renal Injury Prevention 4: 20-27.

\section{[PubMed]}

2. Simmons MN, Schreiber MJ, Gill IS (2008) Surgical renal ischemia: a contemporary overview. Journal of Urology 180: 19-30.

3. Snoeijs MG, van Heurn LW, Buurman WA (2010) Biological modulation of renal ischemia-reperfusion injury. Curr Opin Organ Transplant 15: 190-199. [PubMed]

4. Salvadori M, Rosso G, Bertoni E (2015) Update on ischemia-reperfusion injury in kidney transplant: pathogenesis and treatment, World J Transplant 5: 52-67. [PubMed]

5. Ponticelli C (2014) Ischemia-reperfusion injury: a major protagonist in kidney transplantation. Nephrol Dial Transplant 29: 1134-1140. [PubMed]

6. Salem HK, Thiemermann C (2010) Mesenchymal stromal cells: current understanding and clinical status. Stem Cells 28: 585-596. [PubMed]

7. Pittenger MJ, Mackay AM, Beck SC, Jaiswal RK, Douglas R, et al. (1999) Multilineage potential of adult human mesenchymal stem cells. Science 284 : 143-147. [PubMed]

8. Donizetti-Oliveira C, Semedo P, Burgos-Silva M, Cenedeze MA, Malheiros DM, et al. (2012) Adipose tissue-derived cell transplant prevents renal disease progression. Cell Transplantation 21: 1727-1741. [PubMed]

9. Choi S, Park M, Kim J, Hwang S, Park S, et al. (2009) The role of mesenchymal stem cells in the functional improvement of chronic renal failure. Stem Cells Dev 18: 521-529. [PubMed]

10. Souidi N, Stolk M, Seifert M (2013) Seifert, Ischemia-reperfusion injury: beneficial effects of mesenchymal stromal cells, Curr Opin Organ Transplant 18: 34-43. [PubMed]

11. Morigi M, Introna M, Imberti B, Corna D, Abbate M, et al. (2008) Human bone marrow mesenchymal stem cells accelerate recovery of acute renal injury and prolong survival in mice, Stem Cells 26: 2075-2082. [PubMed]

12. Tögel F, Cohen A, Zhang P, Yang Y, Hu Z, et al. (2009) Autologous and allogenic marrow stromal cells are safe and effective for treatment of acute kidney injury. Stem Cells Dev 18: 475-485. [PubMed]

13. Liang CJ, Shen WC, Chang FB, Wu VC, Wang SH, et al. (2015) Endothelia progenitor cells derived from Wharton's jelly of human umbilical cord attenuate ischemic acute kidney injury by increasing vascularization and decreasing apoptosis, inflammation, and fibrosis. Cell Transplant 24: 1363-1377. [PubMed]

14. Gao J, Dennis JE, Muzic RF, Lundberg M, Caplan Al (2001) The dynamic in vivo distribution of bone marrow-derived mesenchymal stem cells after infusion. Cells Tissues Organs 169: 12-20. [PubMed]

15. Lam PK, Ng CF, To KF, Ng SS, Mak TW, et al. (2011) Topical application of mesenchymal stem cells to somatic organs-a preliminary report. Transplantation 92: e9-11. [PubMed]

16. Lam PK, Lo AW, Wang KK, Lau HC, Leung KK, et al. (2013) Transplantation of mesenchymal stem cells to the brain by topical application in an experimenta traumatic injury model. Journal of Clinical Neuroscience 20: 306-309. [PubMed] 
Citation: Lam P, Chi-fai NG, Tang W, Lo AWI, Tong CSW, et al. (2017) Topical Application of Adipose Tissue-Derived Mesenchymal Stem Cells Ameliorates Renal Ischemia-Reperfusion Injury in Rats. J Stem Cell Res Ther 7: 404. doi: 10.4172/2157-7633.1000404

Page 9 of 9

17. Chiao H, Kohda Y, McLeroy P, Craig L, Housini I, Star RA (1997) Alphamelanocyte-stimulating hormone protects against renal injury after ischemia in mice and rats, J Clin Invest 99: 1165-1172. [PubMed]

18. Chatterjee PK, Brown PA, Cuzzocrea S, Zacharowski K, Stewart KN, et al. (2001) Calpain inhibitor-1 reduces renal ischemia/reperfusion injury in the rat, Kidney International 59: 2073-2083. [PubMed]

19. Schroppel B, Legendre C (2014) Delayed kidney graft function: from mechanism to translation. Kidney Int 86: 251-258. [PubMed]

20. Behr L, Hekmati M, Lucchini A, Houcinet K, Faussat AM, et al. (2009) Evaluation of the effect of autologous mesenchymal stem cell injection in a large-animal model of bilateral kidney ischaemia reperfusion injury, Cell Prolif 42: 284-297. [PubMed]

21. Feng Z, Ting J, Alfonso Z, Strem BM, Fraser JK, et al. (2015) Fresh and cryopreserved, uncultured adipose tissue-derived stem and regenerative cells ameliorate ischemia-reperfusion-induced acute kidney injury. Nephrol Dial Transplant 25: 3874-3884. [PubMed]

22. Friedenstein AJ, Chailakhyan RK, Gerasimov UV (1987) Bone marrow osteogenic stem cells: in vitro cultivation and transplantation in diffusion chambers. Cell and Tissue Kinetics 20: 263-272. [PubMed]

23. Fortier LA (2005) Stem cells: classifications, controversies, and clinical applications. Vet Surg 34: 415-423. [PubMed]

24. da Silva Meirelles L, Caplan AI, Nardi NB (2008) In search of the in vivo identity of mesenchymal stem cells. Stem Cells 26: 2287-2299. [PubMed]

25. Kern S, Eichler H, Stoeve J, Klüter H, Bieback K (2006) Comparative analysis of mesenchymal stem cells from bone marrow, umbilical cord blood, or adipose tissue. Stem Cells 24: 1294-1301. [PubMed]

26. Tögel F, Hu Z, Weiss K, Isaac J, Lange C, et al. (2005) Administered mesenchymal stem cells protect against ischemic acute renal failure through differentiation-independent mechanisms. Am J Physiol Renal Physiol 289: F31-F42. [PubMed]

27. Lange C, Tögel F, Ittrich H, Clayton F, Nolte-Ernsting C, et al. (2005) Administered mesenchymal stem cells enhance recovery from ischemia/ reperfusion-induced acute renal failure in rats, Kidney International 68: 16131617. [PubMed]

28. Behr L, Hekmati M, Fromont G, Borenstein N, Noel LH, et al. (2007) Intra renal arterial injection of autologous mesenchymal stem cells in an ovine model in the postischemic kidney, Nephron Physiology 107: 65-76. [PubMed]

29. Semedo P, Wang PM, Andreucci TH, Cenedeze MA, Teixeira VP, et al. (2007)
Mesenchymal stem cells ameliorate tissue damages triggered by renal ischemia and reperfusion injury. Transplantation Proceedings 39: 421-423. [PubMed]

30. Schrepfer S, Deuse T, Reichenspurner H, Fischbein MP, Robbins RC, et al (2007) Stem cell transplantation: the lung barrier. Transplantation Proceedings 39: 573-576. [PubMed]

31. Lin F, Moran A, Igarashi $P$ (2005) Intrarenal cells, not bone marrow-derived cells, are the major source for regeneration in postischemic kidney, J Clin Invest 115: 1756-1764. [PubMed]

32. Gupta S, Verfaillie C, Chmielewski D, Kim Y, Rosenberg ME (2002) A role for extrarenal cells in the regeneration following acute renal failure, Kidney Int 62 1285-129. [PubMed]

33. Spotnitz WD, Burks S (2008) Hemostats, sealants, and adhesives: components of the surgical toolbox. Transfusion 48: 1502-1516. [PubMed]

34. Pursifull NF, Morey AF (2007) Tissue glues and nonsuturing techniques. Current Opinion in Urology 17: 396-401.

35. Thompson T, Ng CF, Tolley D (2003) Renal parenchymal hemostatic aids: glues and things. Current Opinion in Urology 13: 209-214.

36. Meana A, Iglesias J, Del Rio M, Larcher F, Madrigal B, et al. (1998) Large surface of cultured human epithelium obtained on a dermal matrix based on living fibroblast-containing fibrin gels. Burns 24: 621-630. [PubMed]

37. Yamada Y, Boo JS, Ozawa R, Nagasaka T, Okazaki Y, et al. (2003) Bone regeneration following injection of mesenchymal stem cells and fibrin glue with a biodegradable scaffold. J Craniomaxillofac Surg 31: 27-33. [PubMed]

38. Pan HC, Yang DY, Chiu YT, Lai SZ, Wang YC, et al. (2006) Enhanced regeneration in injured sciatic nerve by human aminiotic mesenchymal stem cell, J Clin Neurosci 13: 570-575. [PubMed]

39. Mizuno H (2009) Adipose-derived stem cells for tissue repair and regeneration: ten years of research and a literature review. J Nippon Med Sch 76: 56-66. [PubMed]

40. Chen YT, Sun CK, Lin YC, Chang LT, Chen YL, et al. (2011) Adipose-derived mesenchymal stem cell protects kidneys against ischemia-reperfusion injury through suppressing oxidative stress and inflammatory reaction, J Transl Med 9: 51. [PubMed]

41. Bi B, Schmitt R, Israilova M, Nishio H, Cantley LG (2007) Stromal cells protect against acute tubular injury via an endocrine effect. JASN 18: 2486-2496.

42. Asanuma H, Meldrum DR, Meldrum KK (2010) Therapeutic applications of mesenchymal stem cells to repair kidney injury, Journal of Urology 184: 26-33. 